$$
\begin{array}{c|l}
\text { Jurnal Sains Komputer dan Teknologi Informasi } & \text { Page } \\
\text { e-issn: 2655-7460. Volume } 3 \text { No.2, Mei 2021 } & 18-28 \\
\hline
\end{array}
$$

\title{
ANALISIS KEKAYAAN MEDIA DAN KEGUNAAN SISTEM LAYANAN ASPIRASI DAN INFORMASI
}

\author{
Fransiskus M. H. Tjiptabudi' \\ 1)Program Studi Sistem Informasi \\ Sekolah Tinggi Manajemen Informatika Komputer (STIKOM) Uyelindo \\ Jl. Perintis Kemerdekaan I, Kota Kupang, Nusa Tenggara Timur \\ Email: tjiptabudifrans@gmail.com
}

\begin{abstract}
ABSTRAK
Sistem Layanan Aspirasi dan Informasi (Selma) yang diterapkan pada Kelurahan Oebufu, Kota Kupang merupakan sebuah bentuk implementasi Sistem Pemerintahan Berbasis Elektronik (SPBE). Selma dibangun sebagai media informasi dan komunikasi seiring dengan program pemerintahan digital melayani guna mencapai tata kelola pemerintahan yang baik (good governance) pada era revolusi industri 4.0. Setelah diimplementasi, Selma yang terdiri dari aplikasi berbasis Android dan SMS Gateway ini perlu dievaluasi dari berbagai segi guna mengetahui apakah Selma telah mampu mencapai tujuannya yakni membantu aparatur dan masyarakat Kelurahan Oebufu. Mengingat Selma sendiri memiliki tugas khusus sebagai media informasi dan komunikasi maka pada penelitian ini akan ditujukan untuk menganalisis kekayaan media dan kegunaannya untuk mengetahui sejauh mana manfaat Selma guna mendukung pemerintahan digital melayani, serta memberi rekomendasi untuk perbaikan Selma ke depannya dengan melakukan analisis berdasarkan metode Media Richness Theory (MRT) dan System Usability Scale (SUS). Adapun hasil yang diperoleh adalah Selma mampu menjadi media yang cukup "kaya" sehingga representatif sebagai media informasi dan komunikasi serta memperoleh rerata skor SUS sebesar 87,7, dengan tingkat penerimaan termasuk dalam kategori "acceptable", tingkat skala kegunaan termasuk dalam kategori "B", dan adjective rating termasuk dalam kategori "excellent".

Kata kunci: Good governance, MRT, SPBE, SUS.
\end{abstract}

\section{ABSTRACT}

The Aspiration and Information Service System (Selma) that implemented in Oefufu Vilage, Kupang City is a form of implementing an Electronic-Based Government System (SPBE). Selma was built as an information and communication media in line with the digital government program serving in order to achieve good governance in the industrial revolution 4.0 era. After being implemented, Selma which consists of an Android-based application and SMS Gateway, needs to be evaluated in order to find out whether Selma has been able to achieve its goal for helping the apparatus and the people of Oebufu Village. Selma has a special task as an information and communication media. This research has a purpose to analyze the richness and usability to find out the extent of Selma's benefits to support digital government serving, and providing recommendations for Selma improvement in the future by conducting analysis based on the MRT and SUS methods. The results obtained are that Selma can be a rich media so it is representative as an information and communication media and has an average SUS score of 87.7, with the acceptance level included in the "acceptable" category, the usability scale level is included in the category. "B", and the adjective rating is included in the "excellent" category.

Keywords: Good governance, MRT, SPBE, SUS.

\section{PENDAhUluan}

Dalam rangka mewujudkan good governance dan untuk mendukung kebijakan SPBE maka Kelurahan Oebufu telah membangun dan menerapkan beberapa sistem berbasis teknologi, salah satunya yakni Sistem Layanan Aspirasi dan Informasi (Selma). Selma merupakan sistem multiplatform dalam bentuk aplikasi Android dan SMS gateway berbasis web service. Sistem ini 
Fransiskus M. H. Tjiptabudi. Analisis Kekayaan Media Dan Kegunaan Sistem Layanan 2021 Aspirasi dan Informasi

lahir sebagai pendukung layanan informasi publik kelurahan guna mencapai penyelenggaraan pemerintahan yang transparan, efektif, efisien, akuntabel dan dapat dipertanggungjawabkan sesuai dengan amanat Undang-Undang nomor 14 tahun 2008 tentang Keterbukaan Informasi Publik.

Sebagai media informasi dan komunikasi, Selma perlu dievaluasi dari segi kekayaan media dan kebergunaannya guna mengetahui apakah Selma telah mampu mencapai tujuannya yakni sebagai pendukung layanan informasi pada Kelurahan Oebufu, untuk mengetahui sejauh mana manfaat Selma guna mendukung pemerintahan digital melayani, serta memberi rekomendasi untuk perbaikan Selma ke depannya. Evaluasi terhadap Selma penting dilakukan karena investasi yang sangat besar dari pemerintah dalam memberikan layanan berbasis elektronik dan juga karena laju pertumbuhan yang besar dalam penerapan SPBE (Rochmansjah, 2019).

Adapun penelitian-penelitian sebelumnya telah mengkaji bagaimana performa sebuah media jika dilihat dari aspek kekayaan media dan kebergunaannya, tetapi penelitian-penelitian tersebut belum mengkombinasikan kedua aspek yang dimaksud dalam penelitian yang sama. Ndaumanu mengevaluasi laman pariwisata Provinsi Kalimantan Barat dengan menggunakan teori MRT. MRT digunakan karena memiliki unsur yang lengkap dan baik digunakan untuk penentuan media komunikasi yang paling tepat untuk menghadapi ketidakpastian dan ketidakjelasan dari informasi (Ndaumanu, 2019). Pada penelitian lainnya, SUS digunakan untuk menganalisis kebergunaan dari berbagai jenis sistem informasi. SUS menjadi metode yang sering digunakan karena dapat dilihat dari pernyataan-pernyataan yang terdapat pada kuesioner SUS sudah mencakup berbagai aspek dari usability suatu sistem (Akhsan dan Faizah, 20l7).

Pada penelitian ini akan dilakukan analisis terhadap Selma sebagai sebuah media informasi dan komunikasi dengan menggunakan metode Media Richness Theory (MRT) dan System Usability Scale (SUS).

\section{TINJAUAN PUSTAKA}

\section{I. Media Richness Theory (MRT)}

Media dianggap "kaya" jika memungkinkan untuk umpan balik segera, beberapa isyarat sekaligus, mampu digunakan dalam berbagai ragam bahasa dan personalisasi. Semakin tinggi tingkatan kekayaan media, maka semakin banyak informasi yang diberikan dan semakin sedikit ketidakjelasan di dalamnya, dan pada gilirannya akan mengurangi tingkat ambiguitas dan ketidakpastian penerima informasi (Daft and Lengel, 1986). Kekayaan media menggunakan empat faktor untuk mengevaluasi kekayaannya yaitu kapasitas media untuk umpan balik segera, jumlah isyarat yang digunakan, jumlah saluran yang digunakan dan berbagai personalisasi dan bahasa (Rui et al, 20I I)

Media Richness Theory (MRT) adalah teori yang paling banyak digunakan dalam pemilihan media komunikasi. MRT pertama kali diperkenalkan oleh Daft and Lengel yang menyatakan bahwa kebergunaan suatu media ditentukan oleh "kekayaan"-nya (richness). MRT berkenaan dengan penentuan media komunikasi yang paling tepat untuk menghadapi ketidakpastian dan ketidakjelasan dari informasi (Daft and Lengel, 1986). Berdasarkan MRT, media komunikasi dapat diranking dan digambarkan secara kontinyu berdasarkan kemampuannya dalam menangani ketidakpastian dan ketidakjelasan.

Daft dan Lengel (1986) mengusulkan empat kriteria untuk menilai media, yaitu kesegeraan (immediacy), keragaman isyarat (multiple cues), variasi bahasa (language variety) dan sumber personal (personal source). MRT dibangun dengan anggapan bahwa peningkatan "kekayaan" dari suatu media terkait dengan kehadiran sosial atau fisik (Zmud et al, 1990).

Untuk memperhitungkan potensi teknologi komunikasi modern yang makin berkembang tersebut, Lodhia kemudian menambahkan kriteria lain untuk menilai kekayaan media, yaitu keragaman penerima (multiple addressibility), perekaman eksternal (externally recordable), memori terolahkan melalui komputer (computer processable memory) dan konkurensi (concurrency) (Lodhia, 2006).

\subsection{System Usability Scale (SUS)}

Usability atau kebergunaan adalah kemampuan produk perangkat lunak untuk dipahami, dipelajari, digunakan, dan menarik bagi pengguna, dalam kondisi tertentu (Bevan, 200I).

Evaluasi kebergunaan yang akan dilakukan terhadap Selma merujuk pada metode System Usability Scale (SUS). SUS digunakan karena menurut Brooke, 


$$
\begin{array}{c|l}
\text { Jurnal Sains Komputer dan Teknologi Informasi } & \text { Page } \\
\text { e-issn: 2655 -7460. Volume 3 No.2, Mei 2021 } & 18-28 \\
\hline
\end{array}
$$

kebergunaan dari sebuah aplikasi dapat diukur menggunakan evaluasi post study dengan metode SUS. SUS merupakan paket evaluasi kebergunaan yang efektif dan handal untuk digunakan pada berbagai produk dan aplikasi (Broke, 2013). SUS terdiri dari 10 pernyataan dengan menggunakan skala likert I sampai 5. Pernyataan nomor ganjil $(I, 3,5,7,9)$ merupakan pernyataan yang bersifat positif, sedangkan pernyataan nomor genap ( 2 , $4,6,8,10)$ merupakan pernyataan yang bersifat negatif seperti yang ditunjukkan pada Tabel I. Responden diminta menjawab semua butir pernyataan SUS setelah pengguna selesai menggunakan sistem secara keseluruhan.

\begin{tabular}{|c|c|c|}
\hline Kode & $\begin{array}{c}\text { Butir Instrumen } \\
\text { Asli }\end{array}$ & $\begin{array}{c}\text { Butir Instrumen } \\
\text { Penelitian }\end{array}$ \\
\hline QI & $\begin{array}{l}\text { I think that I would } \\
\text { like to use this } \\
\text { system frequently. }\end{array}$ & $\begin{array}{l}\text { Saya berpikir bahwa } \\
\text { saya akan sering } \\
\text { menggunakan Selma. }\end{array}$ \\
\hline Q2 & $\begin{array}{l}\text { I found the system } \\
\text { unnecessarily } \\
\text { complex. }\end{array}$ & $\begin{array}{l}\text { Saya menemukan } \\
\text { bahwa Selma terlalu } \\
\text { kompleks (memuat } \\
\text { banyak hal yang tidak } \\
\text { perlu) }\end{array}$ \\
\hline Q3 & $\begin{array}{l}\text { I thought the system } \\
\text { was easy to use. }\end{array}$ & $\begin{array}{l}\text { Saya berpikir bahwa } \\
\text { Selma mudah } \\
\text { digunakan. }\end{array}$ \\
\hline Q4 & $\begin{array}{l}\text { I think that I would } \\
\text { need the support of } \\
\text { a technical person } \\
\text { to be able to use } \\
\text { this system. }\end{array}$ & $\begin{array}{l}\text { Saya pikir bahwa } \\
\text { dibutuhkan bantuan } \\
\text { teknis untuk dapat } \\
\text { menggunakan Selma. }\end{array}$ \\
\hline Q5 & $\begin{array}{l}\text { I found the various } \\
\text { functions in this } \\
\text { system were well } \\
\text { integrated. }\end{array}$ & $\begin{array}{l}\text { Saya menemukan } \\
\text { berbagai fungsi pada } \\
\text { Selma terintegrasi } \\
\text { dengan baik. }\end{array}$ \\
\hline Q6 & $\begin{array}{l}\text { I thought there was } \\
\text { too much } \\
\text { inconsistency in this } \\
\text { system. }\end{array}$ & $\begin{array}{l}\text { Saya pikir bahwa } \\
\text { terlalu banyak } \\
\text { inkonsistensi pada } \\
\text { Selma. }\end{array}$ \\
\hline Q7 & I would imagine that & Saya membayangkan \\
\hline
\end{tabular}

Tabel I. Perbandingan instrumen

\begin{tabular}{lll}
\hline & $\begin{array}{l}\text { most people would } \\
\text { learn to use this } \\
\text { system very quickly. }\end{array}$ & $\begin{array}{l}\text { bahwa kebanyakan } \\
\text { orang akan belajar } \\
\text { menggunakan Selma } \\
\text { dengan sangat cepat. }\end{array}$ \\
\hline Q8 & I found the system & Saya menemukan \\
& very cumbersome to \\
use. & bahwa Selma sangat \\
Q9 & I felt very confident & Saya merasa sangat \\
& using the system. & yakin menggunakan \\
& & Selma. \\
\hline I needed to learn a & Saya perlu belajar \\
lot of things before I & banyak hal sebelum \\
could get going with & saya dapat \\
this system. & menggunakan Selma. \\
\hline Likert scale: & Skala Likert: \\
I: Strongly & I: Sangat Tidak Setuju, \\
Disagree, & 2: Tidak Setuju, \\
2: Disagree, & 3: Netral, \\
3: Neutral -neither & 4: Setuju, \\
Agree nor Disagree, & 5: Sangat Setuju \\
4: Agree, & \\
5: Strongly Agree & \\
\hline & &
\end{tabular}

Setelah data kuesioner yang diberikan kepada responden terkumpul, selanjutnya akan melakukan konversi tanggapan responden dengan cara (Soejono et al, 2018):

a. Pernyataan ganjil: yaitu I, 3, 5, 7, dan 9 skor yang diberikan oleh responden dikurangi dengan I. Skor SUS ganjil $=\Sigma \mathrm{Px}-\mathrm{I}$, yang mana $\mathrm{Px}$ adalah jumlah pertanyaan ganjil.

b. Pernyataan genap: yaitu 2, 4, 6, 8, dan 10 skor yang diberikan oleh responden digunakan untuk mengurangi 5. Skor SUS genap $=\Sigma 5-\mathrm{Pn}$, yang mana $\mathrm{Pn}$ adalah jumlah pertanyaan genap.

c. Skor untuk setiap responden: hasil dari konversi tersebut selanjutnya dijumlahkan untuk setiap responden kemudian dikalikan dengan 2,5 agar mendapatkan rentang nilai antara 0-100 dengan rumus ( $\Sigma$ skor ganjil $-\Sigma$ skor genap) $\times 2,5$.

d. Skor SUS: setelah skor dari masing-masing responden telah diketahui, langkah selanjutnya adalah mencari skor rata-rata dengan cara menjumlahkan semua hasil skor dan dibagi dengan jumlah responden yang ada. Perhitungan ini dapat 
dilihat dengan rumus $\bar{X}=\Sigma x n$, yang mana $\bar{X}$ adalah skor rata-rata, $\Sigma_{x}$ adalah jumlah skor SUS dan $n$ adalah jumlah dari responden. Skor akhir SUS akan berada pada kisaran 0-100.

Dari hasil tersebut akan diperoleh suatu nilai ratarata dari seluruh penilaian skor responden. Untuk menentukan grade hasil penilaian, terdapat dua (2) cara yang dapat digunakan (Ependi et al, 2017). Penentuan pertama dilihat dari sisi tingkat penerimaan pengguna, grade skala dan adjektif rating yang terdiri dari tingkat penerimaan pengguna terdapat tiga kategori yaitu not acceptable, marginal dan acceptable. Sedangkan dari sisi tingkat grade skala terdapat enam skala yaitu A, B, C, D, E dan F. Dan dari adjektif rating terdiri dari worst imaginable, poor, ok, good, excellent dan best imaginable. Penentuan yang kedua dilihat dari sisi percentile range
(SUS skor) yang memiliki grade penilaian yang terdiri dari A, B, C, D dan E. Penentuan hasil penilaian berdasarkan SUS score percentile rank dilakukan secara umum berdasarkan hasil perhitungan penilaian pengguna. Kedua penentuan ini dapat dilihat pada tabel dan gambar berikut ini (Ependi et al, 2019):

Tabel 2. Pemeringkatan persentil dari skor SUS

\begin{tabular}{cc}
\hline Grade & Keterangan \\
\hline A & Skor $>=91$ \\
\hline B & Skor $>=81$ dan $<91$ \\
\hline C & Skor $>=7 \mid$ dan $<81$ \\
\hline$D$ & Skor $>=61$ dan $<71$ \\
\hline F & Skor $<61$ \\
\hline
\end{tabular}

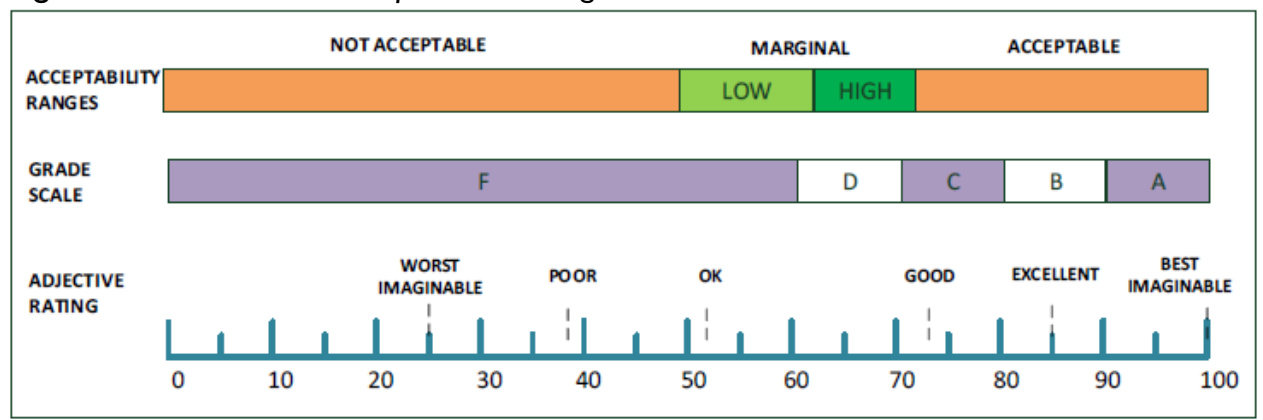

Gambar I. Tingkatan skor SUS

\subsection{Uji Validitas}

Uji validitas digunakan untuk mengukur keabsahan atau validitas sebuah kuesioner. Kuesioner dikatakan valid jika butir pertanyaan/pernyataan kuesioner mampu mengungkapkan sesuatu yang akan diukur oleh kuesioner tersebut dan dapat dicari dengan rumus sebagai berikut (Priyatno, 20I2):

$r_{x y}=\frac{N\left(\sum \mathrm{XY}\right)-\left(\sum \mathrm{X} \sum \mathrm{Y}\right)}{\sqrt{\left(N \sum X^{2}-\left(\sum X\right)^{2}\right)\left(N \sum y^{2}-\left(\sum y\right)^{2}\right)}}$

(I)

Keterangan:

$r_{x y}=$ Koefisien korelasi butir-total (bivariate pearson)

$X=$ Skor butir

$Y=$ Skor total

$\mathrm{N}=$ Banyaknya subjek

Pengujian menggunakan uji dua sisi dengan taraf signifikansi 0,05 . Adapun kriteria pengujian adalah jika nilai Sig. (2-tailed) $<\alpha(0,05)$ maka instrumen atau butir pertanyaan/pernyataan berkorelasi signifikan terhadap skor total (dinyatakan valid), sedangkan jika nilai Sig. (2tailed) $>\alpha(0,05)$ maka instrumen atau butir pertanyaan/pernyataan tidak berkorelasi signifikan terhadap skor total (dinyatakan tidak valid) (Priyatno, 20I2).

\subsection{Uji Reliabilitas}

Instrumen yang reliabel adalah instrumen yang bila digunakan beberapa kali untuk mengukur objek yang sama, akan menghasilkan data yang sama (Sugiyono, 2016). Uji statistik yang digunakan adalah Cronbach's Alpha, dengan penafsiran hasil sebagai berikut:

Tabel 3. Kategori reliabilitas instrumen

\begin{tabular}{cc}
\hline Alpha $>0,90$ & Reliabilitas sempurna \\
\hline Alpha antara 0,70-0,90 & Reliabilias tinggi \\
\hline Alpha antara 0,50-0,70 & Reliabilitas moderat \\
\hline Alpha $<0,50$ & Reliabilitas rendah \\
\hline
\end{tabular}




\begin{tabular}{r|l} 
Jurnal Sains Komputer dan Teknologi Informasi & Page \\
e-issn: 2655-7460. Volume 3 No.2, Mei 2021 & $18-28$ \\
\hline
\end{tabular}

Adapun rumus yang digunakan yakni:

$$
r_{11}=\left[\frac{k}{k-1}\right]\left[\frac{1-\sum \sigma_{b}^{2}}{\sigma_{1^{2}}}\right]
$$

Keterangan:

$r_{11} \quad=$ Reliabilitas instrumen

$k=$ Banyaknya butir pertanyaan/pernyataan

$\sum \sigma b^{2}=$ Jumlah varian butir

$\sigma \mathrm{I}^{2}=$ Varian total

\section{METODE PENELITIAN}

Metode penelitian yang diterapkan pada penelitian ini yaitu kombinasi antara metode kualitatif dan kuantitatif. Metode kualitatif digunakan untuk menganalisis kekayaan media dari Selma sebagai media informasi dan komunikasi yang pengumpulan datanya menggunakan cara observasi dengan berpatokan pada kriteria-kriteria dari Media Richness Theory (MRT), sedangkan metode kuantitatif digunakan untuk menganalisis kebergunaan dari Selma dengan menggunakan kuesioner yang disusun berdasarkan System Usability Scale (SUS) untuk pengumpulan datanya.

Pada penelitian ini, yang menjadi populasi penelitian adalah pemakai akhir Selma yaitu seluruh aparatur kelurahan berjumlah 16 orang serta masyarakat Kelurahan Oebufu yang berdasarkan sensus penduduk tahun 2020 berjumlah 13.789 jiwa. Untuk perkembangan jumlah penduduk terbaru belum dilakukan sensus sehingga populasi dianggap tidak diketahui pasti. Maka untuk penentuan jumlah responden mengacu pada pernyataan Hair et al bahwa banyaknya sampel sebagai responden harus disesuaikan dengan banyaknya indikator pernyataan yang akan digunakan pada kuesioner, dengan asumsi $\mathrm{n} \times 5$ observed variable (indikator) sampai dengan $\mathrm{n} \times 10$ observed variable (indikator) (Hair et al, 2010). Cara ini digunakan pada populasi yang tidak diketahui dengan pasti jumlahnya. Maka pada penelitian ini, perhitungan untuk penentuan jumlah responden yang digunakan adalah 10 butir pernyataan pada kuesioner dikali 5 sehingga diperoleh 50 responden sebagai sampel.

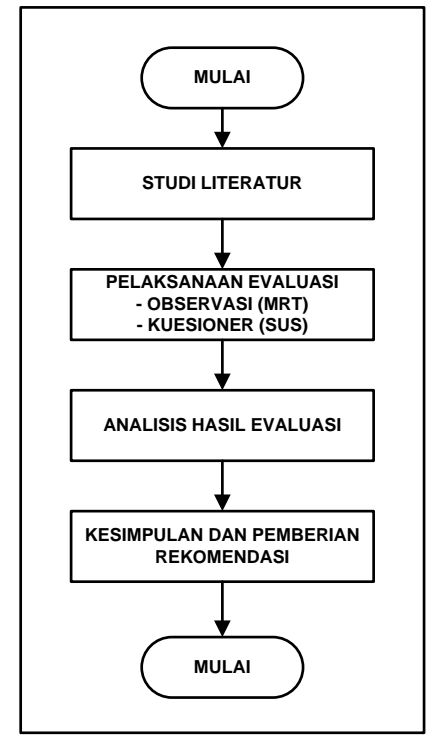

Gambar 2. Tahapan penelitian

Data yang diolah merupakan data primer yaitu berupa hasil observasi dan jawaban responden atas kuesioner yang dibagikan. Selain itu juga digunakan data sekunder yang diperoleh melalui studi literatur. Adapun hipotesis yang dibangun dan akan diuji pada penelitian ini dapat dilihat pada tabel berikut:

Tabel 4. Hipotesis penelitian

\begin{tabular}{cl}
\hline Kode & \multicolumn{1}{c}{ Hipotesis } \\
\hline HI & $\begin{array}{l}\text { Tingkat penerimaan pengguna Selma termasuk } \\
\text { dalam kategori “acceptable” }\end{array}$ \\
\hline H2 & $\begin{array}{l}\text { Tingkat skala kebergunaan/usability Selma } \\
\text { termasuk dalam kategori "A" }\end{array}$ \\
\hline H3 & $\begin{array}{l}\text { Adjective rating kebergunaan/usability Selma } \\
\text { termasuk dalam kategori "excellent" }\end{array}$ \\
\hline
\end{tabular}

\section{HASIL DAN PEMBAHASAN}

\section{I. Analisis Kekayaan Media}

Adapun hasil pengamatan yang dilakukan terhadap Selma berdasarkan unsur-unsur pada MRT akan dibahas satu per satu sebagai berikut:

a. Kesegeraan/Ketepatan Waktu (Immediacy)

Kesegeraan yang dimaksudkan yaitu merujuk kepada kemampuan media dalam menyediakan informasi secara berkala dan memungkinkan umpan balik secara cepat. Jika dilihat pada Selma baik aplikasi Android maupun SMS gateway-nya maka dapat disimpulkan bahwa Selma sebenarnya telah cukup 
Fransiskus M. H. Tjiptabudi. Analisis Kekayaan Media Dan Kegunaan Sistem Layanan 2021 Aspirasi dan Informasi

memenuhi unsur kesegeraan yakni dipublikasikannya informasi-informasi yang berkaitan dengan Kelurahan Oebufu baik berupa pengumuman maupun kegiatan aktual yang dilakukan. Hal ini terlihat dari adanya fitur publikasi berita, galeri kegiatan serta pengumuman.

Meski demikian, yang perlu diperhatikan adalah belum adanya fitur umpan balik dari masyarakat terhadap informasi yang diberikan. Karena pada fitur berita, galeri kegiatan maupun pengumuman tidak disediakan layanan komentar. Begitupun dari aplikasi SMS gateway, masyarakat hanya bisa menerima SMS tanpa perlu membalas.

Berdasarkan hasil analisis tersebut maka perlu untuk memperhatikan beberapa hal yaitu: I) menjaga kesinambungan informasi secara terus menerus, baik berupa berita, kegiatan, maupun pengumuman; 2) setiap informasi harus jelas dan lengkap misalnya ketersediaan deskripsi informasi; 3) tambahkan fasilitas komentar pada setiap postingan; dan 4) sediakan layanan webcast. Webcast sendiri adalah siaran langsung suatu peristiwa dari media internet, sehingga informasi yang ditampilkan tidak hanya sekadar up to date tetapi juga realtime.

b. Keragaman Penerima (Multiple Addressibility)

Keragaman penerima merupakan kemampuan media untuk berkomunikasi serta menyediakan dan menyampaikan informasi ke berbagai pihak. Dalam hal ini Selma memiliki potensi sebagai sarana komunikasi dan informasi massa yang dapat menjangkau pesan secara global dan bisa diakses oleh semua pihak. Adapun beberapa keunggulan Selma yakni dalam penyebaran informasinya, Selma menggunakan platform yang berbeda yakni dalam bentuk aplikasi Android maupun SMS Gateway guna menjangkau semua elemen masyarakat dilihat dari jenis telepon seluler yang digunakan. Keunggulan kedua yaitu tidak adanya fungsi yang dapat membatasi hak akses seperti fungsi login dengan mengisi username dan password. Selma tidak mencantumkan fungsi login sehingga bisa diakses oleh siapapun yang mengakses, terkecuali untuk web servicenya yang hanya bisa diakses oleh admin.

Berdasarkan hasil pengamatan dan analisis yang dilakukan, untuk unsur keragaman penerima direkomendasikan perlu untuk ditambahkan fitur notifikasi pada aplikasi Android. Hal ini berfungsi sebagai peringatan bagi masyarakat yang mungkin jarang mengakses aplikasi Android Selma jika terdapat pembaharuan informasi.

\section{c. Keragaman Isyarat (Multiple Cues)}

Keragaman isyarat mengacu kepada kemampuan untuk mengkomunikasi pesan melalui pendekatan berbeda-beda seperti tubuh, bahasa, suara dan intonasi. Indikator yang dimaksudkan pada unsur ini adalah penggunaan grafis, animasi, multimedia (audio dan video klip) yang dimanfaatkan untuk meningkatkan presentasi dari Selma. Khusus pada aplikasi Android ditemukan keragaman isyarat sebagai bagian dari media informasi pada hampir semua fitur tapi hanya berupa penggunaan foto, sedangkan untuk video hanya berupa tautan pada sumber aslinya.

Adapun kekurangan pada aplikasi Android Selma yakni tidak tersedianya infografis tentang peta yang menunjukkan titik-titik lokasi penting dan juga tidak adanya media komunikasi lain berupa tampilan streaming yang dapat dimanfaatkan untuk meningkatkan presentasi sebagai media informasi dan komunikasi seperti yang telah dibahas pada unsur kesegeraan sebelumnya.

d. Keragaman Bahasa (Language Variety)

Unsur variasi bahasa menunjukkan kemampuan penggunaan kata yang berbeda untuk meningkatkan pemahaman, yaitu pada variasi cara dalam menyampaikan ide dan konsep melalui simbol bahasa. Adapun indikator dari unsur ini adalah apakah institusi dalam hal ini Kelurahan Oebufu memfasilitasi para pihak terkait pada aplikasi dengan menggunakan tautan atau hyperlink, serta menu dan format yang berbeda untuk luaran. Tautan sendiri dibagi menjadi tautan internal (dalam sebuah situs web) dan eksternal (ke situs web lain).

Jika dilihat pada aplikasi Android Selma maka dapat dilihat bahwa terdapat fasilitas tautan, baik internal maupun eksternal. Hal tersebut dapat dilihat dengan adanya tautan ke berbagai fitur yang ada pada aplikasi serta tautan dengan situs web instansi terkait maupun laman berita daring.

Selain adanya fasilitas tautan, unsur keragaman bahasa juga memastikan tersedianya luaran dalam format berkas berbeda seperti Portable Document Format (PDF) atau beberapa format lain yang dapat diunduh. Setelah diamati, Selma belum menyediakan 


\begin{tabular}{c|l|l} 
Jurnal Sains Komputer dan Teknologi Informasi & Page \\
e-issn: 2655-7460. Volume 3 No.2, Mei 2021 & $18-28$ \\
\hline
\end{tabular}

fasilitas luaran yang bisa diunduh dalam format PDF ataupun format lainnya. Kekurangan lainnya adalah Selma juga tidak difasilitasi dengan pemakaian bahasa asing selain bahasa Indonesia.

e. Sumber Personal (Personal Source)

Unsur sumber personal memfokuskan pada kemampuan untuk menunjukkan perasaan dan emosi. Indikator analisisnya adalah memastikan apakah Selma menggunakan tautan ke berbagai pihak dan juga tersedia fasilitas notifikasi atau email alerts untuk memberikan pembaharuan informasi. Pada prinsipnya, unsur ini memiliki sedikit kesamaan dengan unsur keragaman penerima dan keragaman bahasa.

Berdasarkan hasil pengamatan, jelas terlihat bahwa aplikasi Android Selma cukup memenuhi indikator pada unsur ini. Untuk indikator tautan ke berbagai pihak sudah dijelaskan sebelumnya pada unsur keragaman bahasa, yang mana terdapat tautan internal maupun eksternal. Sedangkan layanan notifikasi/email alerts pun telah dibahas pada unsur keragaman penerima, yang mana pada Selma belum menyediakan layanan tersebut sehingga perlu direkomendasikan untuk disediakan pada pengembangan Selma pada masa yang akan datang.

f. Memori Terolahkan Melalui Komputer (Computer Processable Memory)

Memori terolah oleh komputer berarti bahwa informasi dapat diorganisir dan diatur secara elektronik, misalnya tersedia alat-alat untuk membantu navigasi aplikasi seperti fungsi pencarian (search), sitemaps untuk indeksasi laman, dan juga daftar menu.

Berdasarkan indikator-indikator tersebut, sesuai hasil pengamatan pada aplikasi Android Selma belum sepenuhnya terpenuhi. Adapun indikator yang belum terpenuhi yakni adanya fitur sitemaps, sedangkan indikator yang telah terpenuhi adalah tersedianya fitur pencarian serta daftar menu yang diharapkan dapat mendukung penyajian informasi yang dapat memenuhi kebutuhan masyarakat. Terkait permasalahan lengkap atau tidaknya daftar menu atau layanan yang disediakan pada aplikasi Android Selma perlu dilakukan penelitian lebih lanjut.

\section{g. Perekaman Eksternal (Externally Recordable)}

Unsur kriteria perekaman eksternal berhubungan dengan kemampuan untuk menyediakan rekaman komunikasi, termasuk kemampuan untuk mendokumentasikan serta memodifikasi proses komunikasi. Adapun beberapa indikatornya adalah tersedianya fasilitas buku tamu elektronik untuk menginformasikan berapa banyak pengunjung aplikasi, serta tersedianya luaran dari informasi yang menjadi konten dari aplikasi yang dapat diunduh oleh berbagai pihak.

Berdasarkan hasil pengamatan, diketahui bahwa aplikasi Android Selma belum sama sekali memiliki fasilitas-fasilitas tersebut, baik buku tamu maupun unduhan informasi. Khusus untuk fasilitas unduhan informasi, sebelumnya telah dibahas pada unsur keragaman bahasa, yang mana belum disediakan fasilitas luaran yang bisa diunduh oleh masyarakat dalam format PDF ataupun format lainnya.

h. Konkurensi (Concurrency)

Konkurensi merujuk pada kemampuan untuk memfasilitasi interaksi antara banyak pengguna secara simultan. Indikatornya adalah pada Selma harus terdapat fasilitas interaksi melalui email, forum diskusi, bulletin boards, chatroom, automatic feedback forms dan electronic surveys.

Sama seperti hasil pengamatan pada unsur sebelumnya, pada unsur konkurensi ini juga mayoritas indikatornya belum tersedia terkecuali untuk indikator adanya forum diskusi. Pada aplikasi Android terdapat fitur aspirasi yang mana pada fitur ini masyarakat bisa mengirimkan kritik, saran mapun keluhan dan akan ditanggapi oleh aparatur kelurahan maupun oleh Lurahnya secara langsung.

\subsection{Uji validitas}

Uji validitas dilakukan untuk mengukur keabsahan atau validitas sebuah kuesioner yakni yang mana setiap butir pertanyaan/pernyataan kuesioner mampu mengungkapkan sesuatu yang akan diukur oleh kuesioner tersebut. Pada penelitian ini uji validitas dilakukan dengan menggunakan SPSS 25 terhadap jawaban dari 50 responden dengan hasil pada tabel berikut:

Tabel 5. Ringkasan hasil uji validitas

\begin{tabular}{ccccc}
\hline Butir & $\begin{array}{c}\text { Sig. (2- } \\
\text { tailed) }\end{array}$ & $</>$ & $\alpha$ & Kesimpulan \\
\hline Q1 & 0,025 & $<$ & 0,05 & Valid \\
\hline Q2 & 0,002 & $<$ & 0,05 & Valid \\
\hline Q3 & 0,000 & $<$ & 0,05 & Valid \\
\hline Q4 & 0,000 & $<$ & 0,05 & Valid \\
\hline
\end{tabular}


Fransiskus M. H. Tjiptabudi. Analisis Kekayaan Media Dan Kegunaan Sistem Layanan 2021 Aspirasi dan Informasi

\begin{tabular}{ccccc}
\hline Q5 & 0,031 & $<$ & 0,05 & Valid \\
\hline Q6 & 0,000 & $<$ & 0,05 & Valid \\
\hline Q7 & 0,009 & $<$ & 0,05 & Valid \\
\hline Q8 & 0,000 & $<$ & 0,05 & Valid \\
\hline Q9 & 0,028 & $<$ & 0,05 & Valid \\
\hline Q10 & 0,001 & $<$ & 0,05 & Valid \\
\hline
\end{tabular}

Uji validitas dua sisi dengan taraf signifikansi 0,05 menunjukkan bahwa semua butir pernyataan memiliki nilai Sig. (2-tailed) lebih kecil dari taraf signifikansi, sehingga semua butir dinyatakan valid.

\subsection{Uji reliabilitas}

Uji reliabilitas menggunakan Cronbach's Alpha ditampilkan pada Tabel 6. Hasil uji dengan menggunakan SPSS 25 menunjukkan bahwa nilai Cronbach's Alpha untuk 10 butir pernyataan kuesioner yaitu sebesar 0.600 , sehingga kuesioner ini termasuk dalam kategori reliabilitas moderat.

\begin{tabular}{cc}
\hline Cronbach's Alpha & N of Items \\
\hline, 600 & 10 \\
\hline
\end{tabular}

Hasil uji reliabilitas ini menunjukkan bahwa bila kuesioner digunakan beberapa kali untuk mengukur objek yang sama, maka cenderung akan menghasilkan data yang sama.

\subsection{Analisis Kegunaan}

Untuk analisis kebergunaan dari Selma dilakukan dengan perhitungan poin SUS berdasarkan jawaban responden terhadap kuesioner. Pengukuran data pada kuesioner digunakan skala pengukuran Likert dengan skala deskriptif yakni Sangat Setuju (SS) dengan bobot 5, Setuju (S) dengan bobot 4, Ragu-ragu (R) atau Netral (N) dengan bobot 3, Tidak Setuju (TS) dengan bobot 2, Sangat Tidak Setuju (STS) dengan bobot I. Adapun hasil perhitungan jawaban kuesioner menggunakan metode SUS yang dilakukan terhadap 50 responden dapat dilihat pada tabel berikut:

\begin{tabular}{|c|c|c|c|c|c|c|c|c|c|c|c|c|c|c|c|c|c|c|c|c|}
\hline Item & el 6 . & Hassil & 4.ji & eliat & ilitas & R6 & R7 & Rs & $\mathbf{R} 9$ & R10 & Rl1 & $\mathrm{R} 12$ & $\mathrm{R} 13$ & $\mathrm{R} 14$ & R15 & R16 & R17 & R18 & R19 & $\mathbf{R} 20$ \\
\hline Q1 & 4 & 4 & 4 & 4 & 4 & 4 & 4 & 3 & 4 & 4 & 4 & 4 & 4 & 4 & 3 & 4 & 4 & 4 & 4 & 4 \\
\hline Q2 & 4 & 3 & 4 & 4 & 4 & 3 & 4 & 4 & 3 & 3 & 3 & 4 & 4 & 4 & 3 & 4 & 4 & 4 & 4 & 4 \\
\hline Q3 & 4 & 3 & 3 & 3 & 3 & 3 & 4 & 3 & 3 & 3 & 3 & 3 & 4 & 3 & 3 & 3 & 4 & 3 & 3 & 4 \\
\hline Q4 & 4 & 3 & 3 & 3 & 3 & 3 & 4 & 3 & 3 & 3 & 3 & 3 & 4 & 3 & 4 & 3 & 4 & 4 & 4 & 4 \\
\hline Q5 & 4 & 3 & 3 & 4 & 3 & 3 & 4 & 3 & 3 & 4 & 4 & 4 & 3 & 4 & 3 & 3 & 2 & 3 & 4 & 3 \\
\hline Q6 & 4 & 4 & 3 & 3 & 3 & 3 & 4 & 4 & 4 & 4 & 3 & 4 & 4 & 3 & 4 & 3 & 4 & 4 & 4 & 4 \\
\hline Q7 & 4 & 4 & 3 & 3 & 3 & 3 & 4 & 4 & 4 & 4 & 4 & 4 & 4 & 3 & 3 & 3 & 3 & 4 & 3 & 3 \\
\hline Q8 & 4 & 3 & 4 & 3 & 4 & 3 & 4 & 4 & 4 & 3 & 3 & 4 & 4 & 3 & 4 & 4 & 4 & 4 & 4 & 4 \\
\hline Q9 & 4 & 4 & 4 & 4 & 3 & 4 & 4 & 4 & 4 & 4 & 4 & 4 & 4 & 4 & 4 & 4 & 4 & 3 & 4 & 4 \\
\hline Q10 & 4 & 3 & 3 & 3 & 3 & 2 & 3 & 3 & 3 & 3 & 2 & 2 & 3 & 3 & 3 & 3 & 4 & 4 & 4 & 4 \\
\hline \begin{tabular}{|l|} 
Total Skor \\
\end{tabular} & 100 & 85 & 85 & 85 & 82,5 & 77,5 & 97,5 & 87,5 & 87,5 & 87,5 & 82,5 & 90 & 95 & 85 & 85 & 85 & 92,5 & 92,5 & 95 & 95 \\
\hline Item & R21 & R22 & R23 & R24 & R25 & $\mathrm{R} 26$ & R27 & R2s & R29 & R30 & R31 & R32 & R33 & R34 & R35 & R36 & R37 & R38 & R39 & R40 \\
\hline Q1 & 3 & 4 & 4 & 4 & 3 & 4 & 4 & 4 & 4 & 4 & 4 & 4 & 4 & 3 & 4 & 4 & 4 & 4 & 4 & 4 \\
\hline Q2 & 4 & 3 & 4 & 2 & 4 & 3 & 4 & 4 & 3 & 3 & 3 & 4 & 4 & 4 & 3 & 4 & 4 & 3 & 4 & 4 \\
\hline Q3 & 4 & 3 & 3 & 4 & 3 & 3 & 4 & 3 & 3 & 3 & 2 & 3 & 4 & 3 & 3 & 3 & 4 & 3 & 3 & 3 \\
\hline Q4 & 4 & 3 & 3 & 4 & 3 & 3 & 4 & 3 & 3 & 3 & 4 & 3 & 4 & 3 & 4 & 3 & 4 & 4 & 4 & 4 \\
\hline Q5 & 3 & 3 & 3 & 4 & 3 & 3 & 4 & 3 & 3 & 4 & 4 & 4 & 3 & 4 & 3 & 3 & 4 & 3 & 4 & 3 \\
\hline Q6 & 4 & 4 & 3 & 4 & 3 & 3 & 4 & 4 & 4 & 4 & 3 & 4 & 4 & 3 & 4 & 3 & 4 & 4 & 3 & 4 \\
\hline$Q^{7}$ & 3 & 4 & 3 & 3 & 3 & 3 & 4 & 4 & 4 & 4 & 3 & 4 & 4 & 3 & 3 & 3 & 3 & 4 & 3 & 3 \\
\hline Q8 & 3 & 3 & 4 & 3 & 4 & 3 & 4 & 3 & 4 & 3 & 3 & 4 & 4 & 3 & 4 & 3 & 4 & 4 & 4 & 4 \\
\hline Q9 & 3 & 4 & 4 & 4 & 3 & 4 & 4 & 4 & 4 & 4 & 3 & 4 & 4 & 4 & 4 & 4 & 4 & 3 & 4 & 4 \\
\hline Q10 & 4 & 3 & 4 & 3 & 3 & 3 & 3 & 3 & 3 & 3 & 3 & 3 & 3 & 4 & 3 & 3 & 4 & 4 & 3 & 4 \\
\hline \begin{tabular}{|l|} 
Total Skor \\
\end{tabular} & 87,5 & 85 & 87,5 & 87,5 & 80 & 80 & 97,5 & 87,5 & 87,5 & 87,5 & 80 & 92,5 & 95 & 85 & 87,5 & 82,5 & 97,5 & 90 & 90 & 92,5 \\
\hline
\end{tabular}

\begin{tabular}{|c|c|c|c|c|c|c|c|c|c|c|c|}
\hline $\begin{array}{c}\text { Respnd } \\
\text { Item }\end{array}$ & R41 & R42 & R43 & R44 & R45 & R46 & R47 & R48 & R49 & R50 & $\begin{array}{l}\text { Skor } \\
\text { per } \\
\text { Item }\end{array}$ \\
\hline Q1 & 3 & 4 & 3 & 4 & 4 & 4 & 3 & 4 & 4 & 2 & 3,8 \\
\hline Q2 & 4 & 3 & 4 & 3 & 4 & 3 & 4 & 4 & 3 & 3 & 3.6 \\
\hline Q3 & 3 & 3 & 4 & 3 & 3 & 3 & 4 & 3 & 3 & 3 & 3,22 \\
\hline Q4 & 4 & 3 & 4 & 3 & 4 & 3 & 4 & 3 & 3 & 3 & 3,44 \\
\hline Q5 & 4 & 3 & 3 & 4 & 3 & 3 & 4 & 3 & 3 & 3 & 3,36 \\
\hline Q6 & 3 & 4 & 3 & 4 & 3 & 3 & 4 & 4 & 4 & 3 & 3,62 \\
\hline Q7 & 4 & 4 & 3 & 3 & 3 & 3 & 4 & 4 & 4 & 3 & 3,46 \\
\hline Q3 & 3 & 3 & 4 & 3 & 4 & 3 & 4 & 4 & 4 & 3 & 3,6 \\
\hline Q9 & 3 & 4 & 4 & 4 & 3 & 4 & 4 & 3 & 4 & 3 & 3.8 \\
\hline Q10 & 3 & 3 & 3 & 4 & 3 & 3 & 3 & 3 & 3 & 3 & 3,18 \\
\hline Total Skor & 85 & 85 & 87,5 & 87,5 & 85 & 80 & 95 & 87,5 & 87,5 & 72,5 & \\
\hline Rerata & \multicolumn{10}{|c|}{87,7} & \\
\hline
\end{tabular}




\begin{tabular}{c|l} 
Jurnal Sains Komputer dan Teknologi Informasi & Page \\
e-issn: 2655 -7460. Volume 3 No.2, Mei 2021 & 18 28 \\
\hline
\end{tabular}

Tabel 7. Hasil perhitungan SUS

Berdasarkan hasil perhitungan jawaban kuesioner menggunakan metode SUS (Tabel 7), maka dapat diketahui bahwa skor akhir SUS adalah 87,7. Skor tersebut menunjukkan bahwa: I) tingkat penerimaan pengguna Selma termasuk dalam kategori "acceptable";
2) tingkat skala kebergunaan/usability Selma termasuk dalam kategori "B"; 3) adjective rating kebergunaan/usability Selma termasuk dalam kategori "excellent".

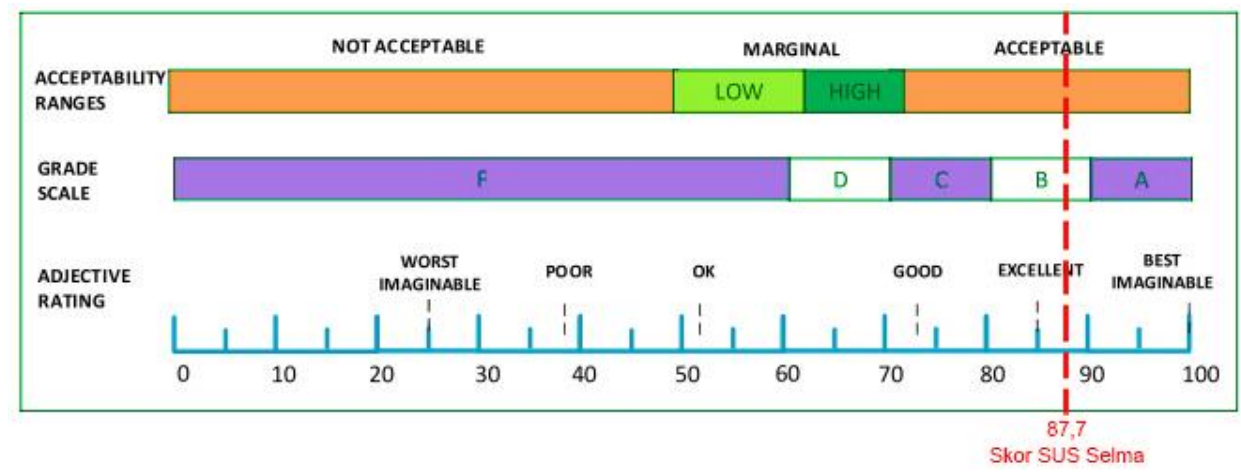

Gambar 3. Tingkat kegunaa Selma

Dengan demikian, berdasarkan hasil tersebut dapat dilihat bahwa dari ketiga hipotesis penelitian yang dibangun, hanya hipotesis $\mathrm{H} 2$ yang menyatakan bahwa tingkat skala kebergunaan/usability Selma termasuk dalam kategori "A" tidak dapat diterima. Skor akhir perhitungan SUS sebesar 87,7 hanya berada pada kategori "B". Untuk kedua hipotesis lainnya yaitu $\mathrm{HI}$ yang menyatakan tingkat penerimaan pengguna Selma termasuk dalam kategori "acceptable" dan $\mathrm{H} 3$ yang menyatakan adjective rating kebergunaan/usability Selma termasuk dalam kategori "excellent" dapat diterima. Secara umum kesimpulan yang diperoleh adalah Selma pada dasarnya diterima oleh responden tetapi perlu dilakukan beberapa perbaikan ke depannya agar dapat meningkatkan kebergunaannya.

Berdasarkan Tabel 7, secara umum terlihat bahwa tidak ada butir yang memperoleh skor maksimal dari 50 orang responden. Hal tersebut menunjukkan keyakinan semua responden bahwa Selma perlu diperbaiki atau dikembangkan. Butir Q9 dan QI menjadi butir yang memperoleh skor butir tertinggi yaitu sebesar 3,8 yang menunjukkan bahwa mayoritas responden yakin untuk menggunakan Selma.

Butir Q3 yang menyatakan responden berpikir bahwa Selma mudah digunakan memperoleh skor butir hanya sebesar 3,22, artinya bahwa kesan awal yang diterima oleh responden pada saat penerapan Selma adalah Selma merupakan sebuah sistem yang menyusahkan atau tidak praktis. Tetapi pemikiran awal responden tersebut terbantahkan pada skor butir Q8 yang menyatakan bahwa responden menilai Selma sangat rumit untuk digunakan memperoleh perbedaan skor cukup signifikan bila dibandingkan dengan butir Q3. Hasil skor butir Q8 dapat menjelaskan bahwa sebenarnya responden hampir tidak menemukan kesulitan pada Selma. Hal tersebut cukup beralasan karena Selma yang dibuat multiplatform agar bisa menjangkau masyarakat dengan penggunaan jenis telpon seluler yang berbeda dan khusus antarmuka aplikasi Android didesain sesederhana mungkin.

Butir Q10 yang menyatakan bahwa responden perlu belajar banyak hal sebelum dapat menggunakan Selma mendapat skor mayoritas 3, bahkan terdapat skor 2 dari beberapa orang responden. Hal tersebut menjadikan butir ini memperoleh skor terendah. Skor tersebut mengindikasikan bahwa butuh waktu dan usaha yang cukup besar bagi para responden agar dapat menggunakan Selma. Setelah ditelusuri faktor penyebabnya adalah bukan karena Selma, melainkan pola kerja atau kebiasaan responden yang sebelumnya belum memanfaatkan teknologi sehingga ketika terjadi perubahan maka para responden membutuhkan adaptasi. Hal inilah yang menyebabkan skor butir Q10 hanya sebesar 3,18. Tetapi, perlu digarisbawahi bahwa 
kebutuhan waktu dan usaha yang cukup besar hanya terjadi di awal penerapan Selma, selebihnya sudah tidak lagi dikarenakan para responden sudah beradaptasi.

Berdasarkan ISO 924I-II:2018, evaluasi kebergunaan bertujuan untuk mengevaluasi sejauh mana suatu sistem, produk atau layanan dapat digunakan oleh pengguna tertentu untuk mencapai tujuan yang telah ditetapkan dengan memperhatikan efektivitas, efisiensi dan kepuasan dalam konteks penggunaan yang ditentukan (ISO, 20I8). Berdasarkan penjelasan tersebut, terdapat 3 (tiga) kata kunci yang harus terpenuhi dalam mengevaluasi kebergunaan sebuah sistem yaitu efektivitas, efisiensi dan kepuasan. Broke menjelaskan maksud dari ketiga kata tersebut yaitu: I) efektivitas, apakah orang dapat benar-benar menyelesaikan tugas dan mencapai tujuan-tujuan mereka; 2) efisiensi, sejauh mana mereka menghabiskan sumber daya untuk mencapai tujuan-tujuan mereka; 3) kepuasan, tingkat kenyamanan yang mereka alami dalam mencapai tujuan-tujuan tersebut. Jadi jika suatu sistem yang memungkinkan orang menyelesaikan tugas-tugas mereka, tetapi dengan mengorbankan waktu dan usaha yang besar dan dirasakan sangat tidak memuaskan oleh semua pihak, tidak dapat dikatakan berguna (Bevan, 200I).

Berdasarkan skor SUS yang diperoleh, jelas bahwa Selma dapat digunakan untuk membantu menyelesaikan tugas para responden dengan nyaman dan tanpa membutuhkan sumber daya dalam jumlah yang besar. Jadi dapat disimpulkan bahwa tiga (3) aspek penting dalam evaluasi kebergunaan sebuah sistem yaitu efektivitas, efisiensi dan kepuasan cukup dapat terpenuhi oleh Selma.

\subsection{Rekomendasi Perbaikan}

Hasil analisis menunjukkan berbagai macam kekurangan pada Selma jika dilihat dari kriteria-kriteria yang ada pada MRT maupun dengan metode SUS. Oleh karena itu maka melalui penelitian ini direkomendasikan beberapa hal guna menjadi pertimbangan dalam rangka perbaikan dan pengembangan Selma pada masa yang akan datang yakni sebagai berikut:

a. Setiap informasi harus dilengkapi dengan deskripsi yang jelas, bila perlu dilengkapi dengan gambar atau video penunjang.

b. Tambahkan fasilitas komentar pada setiap postingan. c. Menerapkan konsep bilingual (bahasa Indonesia dan Inggris).

d. Sediakan layanan infografis, streaming, webcast, kanal media sosial, buku tamu, email alerts atau notifikasi, electronic surveys dan unduhan informasi dalam berbagai format berkas.

e. Integrasikan semua fitur dalam menu yang terstruktur dan jelas.

f. Terapkan user experience untuk meningkatkan kemudahan dalam penggunaan.

\section{KESIMPULAN DAN SARAN}

Berdasarkan hasil penelitian, maka dapat disimpulkan baahwa hasil analisis kekayaan media berdasarkan 8 (delapan) kriteria Media Richness Theory (MRT) terhadap Selma menunjukan bahwa sistem tersebut sudah memenuhi mayoritas indikator-indikator pada setiap kriteria MRT, atau bisa dikatakan bahwa Selma mampu menjadi media yang cukup "kaya" sehingga representatif sebagai media informasi dan komunikasi. Secara umum hasil evaluasi kebergunaan Selma bernilai positif yakni dengan nilai rerata skor SUS sebesar 87,7 dengan tingkat penerimaan termasuk dalam kategori "acceptable", tingkat skala kebergunaan/usability termasuk dalam kategori "B", dan adjective rating termasuk dalam kategori "excellent". Hal tersebut berarti Selma dapat digunakan untuk membantu menyelesaikan tugas-tugas dari para responden dengan memuaskan dan tanpa membutuhkan sumber daya dalam jumlah yang besar. Walaupun hasil analisis menunjukan hal yang positif, tapi bukan berarti Selma tanpa kekurangan. Oleh karena itu perlu memperhatikan beberapa rekomendasi yang diberikan untuk perbaikan dan pengembangan Selma pada masa yang akan datang agar semakin meningkatkan kekayaan dan kebergunaan Selma sebagai media informasi dan komunikasi bagi aparatur dan masyarakat Kelurahan Oebufu. 


\begin{tabular}{c|l} 
Jurnal Sains Komputer dan Teknologi Informasi & Page \\
e-issn: 2655-7460. Volume 3 No.2, Mei 2021 & $18-28$ \\
\hline
\end{tabular}

\section{ACKNOWLEDGEMENT}

Ucapan terima kasih kepada Lurah (Bapak Zet Batmalo, SH. MH.), para aparatur dan masyarakat Kelurahan Oebufu, Kota Kupang, Nusa Tenggara Timur yang telah memberikan dukungan atas partisipasinya sebagai tempat dan responden penelitian.

\section{DAFTAR PUSTAKA}

Akhsan AA., Faizah. 2017. Analisis dan Perancangan Interaksi Chatbot Reminder Dengan Usercentered Design. Jurnal Sistem Informasi (Journal of Information Systems), vol. 2, no. 13, pp. 78-89.

Bevan N. 200I. International Standards for $\mathrm{HCl}$ And Usability. International Journal Human-Computer Studies, vol. 55, pp. 533-552.

Broke J. 2013. SUS : A Retrospective. Journal of Usability Studies, vol. 8, no. 2, pp. 29-40.

Daft LR., Lengel RH. 1986. Organizational Information Requirements, Media Richness and Structural Design. Management Science, vol. 32, no. 5, pp. 554-57I.

Ependi U., Panjaitan F., Hutrianto, H. 2017. System Usability Scale Antarmuka Palembang Guide Sebagai Media Pendukung Asian Games XVIII. Journal of Information Systems Engineering and Business Intelligence (IISEBI), vol. 3, no. 2, pp. 8086.

Ependi U., Kurniawan TB., Panjaitan F. 2019. System Usability Scale Vs Heuristic Evaluation: a Review. Journal Teknik Industri, Mesin, Elektro dan IImu Komputer (SIMETRIS), vol. I0, no. I, Pp. 65-74.

Hair JF., Black W., Babin B., Anderson R. 2010. Multivariate Data Analysis, $7^{\text {th }}$ Edition. New York (US): Prentice Hall International, Inc.

ISO. 2018. Ergonomics of Human-System Interaction - Part II: Usability: Definitions and Concepts. Tersedia pada:

https://www.iso.org/obp/ui/\#iso:std:iso:9241:I I:ed-2:vI:en, diakses 20 September 2020.

Lodhia SK., 2006. The World Wide Web and It's Potential for Corporate Environmental Communication: A Study Into Present Practices In The Australian Minerals Industry. The International Journal of
Digital Accounting Research, vol. 6, no. II, pp. 6594.

Ndaumanu RI. 2019. Analisis Laman Pariwisata Provinsi Kalimantan Barat. Prosiding SEMMAU)5, pp. 889895.

Priyatno D. 2012. Cara Kilat Belajar Analisis Data dengan SPSS 20. Yogyakarta (ID): Andi Offset.

Rochmansjah H. 2019. Kompleksitas Evaluasi Sistem Informasi Elektronic Government Ditinjau Dari Sudut Pandang Publik. Media Bina Ilmiah. vol. 13, no. 10, pp. 1739-1745.

Rui G., Kunihiko H., Douglas RM. 20II. A Study on Communication Media Selection: Comparing the Effectiveness of the Media Richness, Social Influence, and Media Fitness. Journal of Service Science and Management, vol. 4, no. 3, pp. 29I-299.

Soejono AW., Setyanto A., Sofyan AF. 2018. Evaluasi Usability Website UNRIYO Menggunakan System Usability Scale (Studi Kasus: Website UNRIYO), JTIRespati, vol. XIII, no. I, pp. 29-37.

Sugiyono. 2016. Metode Penelitian Kuantitatif, Kualitatif dan R\&D. Bandung (ID): Alfabeta.

Zmud R., Lind M., Young F. 1990. An Attribute Space for Organizatonal Communication Channels. Information Systems Research, vol. I, no. 4, PP. 440-457. 